_ Letzte Woche habe ich meine Mutter zum Frisör begleitet. Das war für uns beide ein ganz besonderes Ereignis. Für meine Mutter, weil sie sich zum ersten Mal ohne Perücke gezeigt hat, und für mich, weil ich einem ganz neuen Menschen gegenübersaß. Denn Brustkrebs und Chemotherapie haben sie verändert - innerlich und äußerlich.

_ Ende letzten Jahres war meine Mutter für drei Wochen in der Reha. Da war ich natürlich neugierig, was die Ergotherapeuten der Einrichtung zur Verbesserung ihrer Lebensqualität beitragen würden. Umso enttäuschter war ich, als ich hörte, dass es lediglich einen einzigen Termin während der ganzen Zeit gab. Wegen ihrer Sensibilitätsstörungen in den Händen und Füßen setzte man sie an ein Rapsbad und gab ihr eine Nadelreizmatte mit aufs Zimmer. Das wars. Keine Befunderhebung, keine weitere Intervention. Ich war schockiert. Denn nach OPs und einer derartig aggressiven Behandlung bleiben körperliche und emotionale Symptome nicht aus. Der gesamte Lebensalltag ist davon betroffen.

_ Darum habe ich mich besonders gefreut, als Viktoria Deimel einen Artikel zur tertiären Prävention bei Brustkrebs eingereicht hat. Die Ergotherapeutin hat ein Kursprogramm entwickelt, das sämtliche Bereiche anspricht, mit denen Frauen nach Brustkrebs zu kämpfen haben. Ich würde mir wünschen, dass möglichst viele Ergotherapeuten ihren Beitrag ab Seite 26 lesen und vielleicht Teile daraus übernehmen oder adaptieren, um betroffenen Frauen wertvolle Unterstützung bieten zu können.

Herzlichst

Ihre

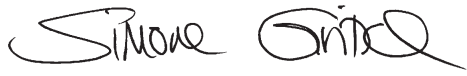

\section{Ungenutztes Potenzial}

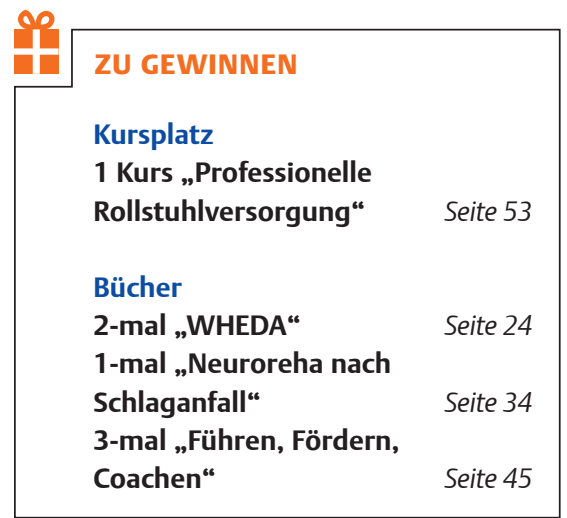

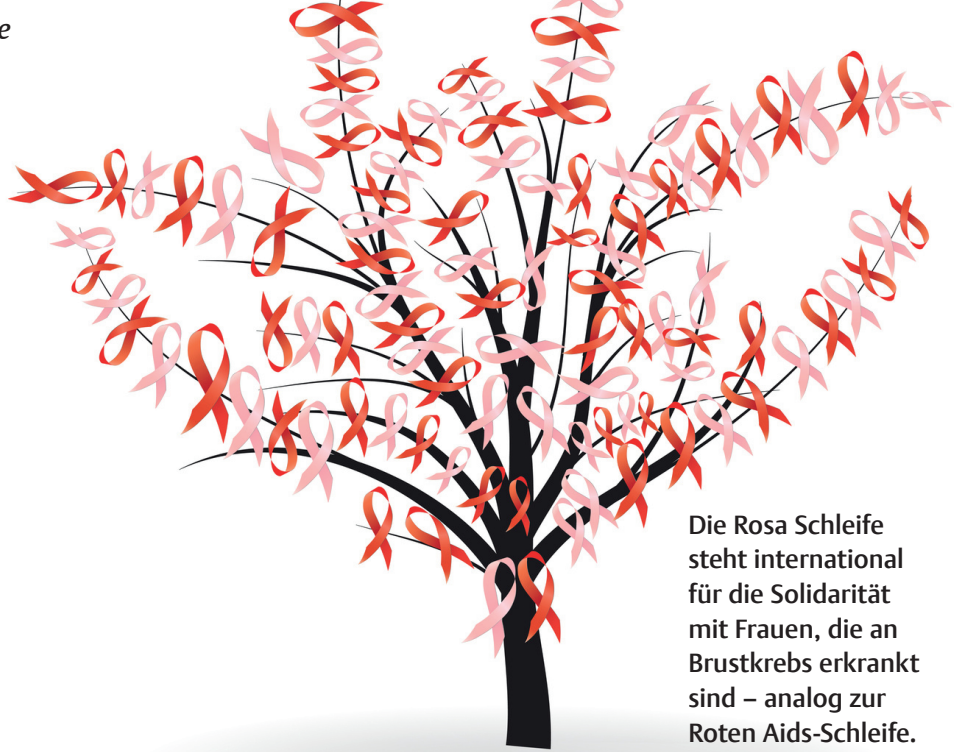

Die Rosa Schleife mit Frauen, die an sind - analog zur Roten Aids-Schleife. 